10 ${ }^{\circ}$ to the left of Capella); from thence it glided slowly across the sky, shining with a brilliant green light, and exhibiting a pearshaped disc of one-third of the apparent diameter of the full moon. When it had arrived at the middle of its path (being almost due north), its velocity abated, and its colour changed to a whitis/l-blue. The meteor, accompanied by a diminutive red tail, and followed by a train of sparks, then regained its original velocity, and gradually approaching the horizon, eventually disappeared behind a cloud lying parallel, and close to the horizon in the N.N.W. The whole time occupied during its flight being $2^{\circ} 5^{\prime \prime}$. In my letter reporting the auroral display of Nov. to last year, I suggested the application of Photography to the solution of auroral problems ; might I venture to ask if any of your photographic correspondents have been able, during the displiys of this year, to prove the possibility of taking auroral photos? I think the results would be interesting to most of your readers.

Glasgow, Nov. 4 ROBERT MCCLURE

ON Wednesday night the 6th November, whilst looking from this place over the sea, directly west, a few minutes before ten o'clock, I saw a meteor of large size subtending I should think one-sixth the angular magnitude of the moon. It was accompanied by a short scintillating train, and moved slowly quite parallel with the horizon directly north. Its elevation was about $15^{\circ}$, and its rate of motion $I$ should think $\mathbf{I}_{2}{ }^{\circ}$ per second. The night was dark and somewhat cloudy, and the line described by the meteor seemingly quite straight.

Blackpool, Nov. 8

\section{Day Aurora}

WITH respect to the "Day Aurora" alleged to have been seen by Secchi (see vol. vi.'p. 492) his description is not that of an aurora, especially as regards its position, which was far from being at right angles to the magnetic meridian; and as regards the "fantastic rays (jets filamenteux)" whose "forms perfectly resembled those of the solar protuberances," they would therefore be very unlike the rays of an aurora. T. W. BACKHOUSE

Sunderland, Oct. $3^{\circ}$

\section{THE KATIPO OR VENOMOUS SPIDER OF}

\section{NEW ZEALAND}

F ROM the interesting "Field Notes of a Naturalist in New Zealand," which have been appearing in the Field for some weeks, we extract the following description of this hitherto little-known animal.

Among the invertebrata there is a venomous spider known as the "katipo ;" and, as this is almost the only noxious inhabitant of the land, it may be interesting to give some account of it, especially as there are some very curious points in its natural history. The first scientific notice of the existence of a poisonous spider in New Zealand was furnished by Dr. Ralph, in a communication to the Linnean Society in 1856 (see Journal Proc. Lin. Soc., vol. i., I856, pp. I, 2). Dr. Ralph's paper contained a short description of the full-grown spider, observations on its nesting habits, and an account of experiments which he had made in order to test the potency of its venom. The native name, katipo, signifies "night stinger" (being derived from two words, kakati, to sting, and po, the night), and, although more strictly applicable to the venomous spider, it is often used to denote a wasp or other stinging insect. The species has been described and figured in the Transactions of the New Zealand Institute (1870, vol. iii. pp. 56-59), under the name of Latrodectus katipo, and is closely allied to, if not identical with, one inhabiting Australia. The exact range of this spider in New Zealand has not been accurately ascertained ; but it appears to be rather local in its distribution, while its habitat is strictly confined to the sand hills skirting the sea-shore. Along the coast from Wainui to
Waikanae (on the north side of Cook's Strait) it is excessively abundant. From Waikanae to Horowhenua it is comparatively scarce ; but at the latter place, and for a few miles farther north, it is said to be abundant. At Manawatu, and thence along the coast for twenty or thirty miles, it is very rare. At the mouth of the Wanganui river, again, it is very abundant ; and a story is still current among the natives of the district about a fishing party, all of whom were bitten by this dreaded spider, and in two cases with fatal results.

The writer then adduces several instances to prove that the bite of the spider is occasionally fatal, and certainly very painful and distressing. But, he says, "I have satisfied myself that, in common with many other venomous creatures, it only exerts its dreaded power as a means of defence, or when greatly irritated; for I have observed that on being touched with the finger it instantly folds its legs, rolls over on its back, and simulates death, remaining perfectly motionless till further molested, when it attempts to escape, only using its fangs as the dernier ressort!"

The cocoon or nest of the katipo is perfectly spherical in shape, opaque, yellowish white, and composed of a silky web of very fine texture. The eggs are of the size of mustard seed, perfectly round, and of a transparent purplish red. They are agglutinated together in the form of a ball, and are placed in the centre of the cocoon, the exterior surface of which is sometimes encrusted with sand. The spider itself undergoes the following changes in its progress towards maturity :-In the very young state it has its body white, with two linear series of connected black spots, and an intermediate line of pale red; under parts brown; legs light brown, with black joints. In the next stage, the fore part of the body is yellow, with two black " eye spots " sides black, with transverse marks of yellowish white; dorsal stripe bright red, commencing higher up than in the adult, and with the edges serrated. At a more advanced age the stripe on the back is brighter, with a narrow border of yellow, and the thorax and legs are nearly black. In the fully adult condition, the female of this spider is very handsome both in form and colour. Examples differ considerably in size, the body, which is almost spherical, varying in development from the size of a pigeon-shot to that of a small green pea; and in the largest specimens the outspread legs, measuring across, cover a space of only three-quarters of an inch; thorax and body shining, satiny black ; a stripe of bright orangered passes down the centre of the body, the edges being tinged with yellow. At the anterior extremity this stripe is broad and angular, and is surmounted by an open narrow mark of white in the form of a nail head; below this, and immediately above the junction of the thorax, there are two divergent spots of orpiment yellow, with white edges; legs black, with the extremities inclining to brown. The male is considerably smaller, and has the body shining blackish-brown, with an obscure narrow line of yellow down the centre of the back, broader towards the posterior extremity, and a similar interrupted line on each side of the body.

The spider here described belongs to a genus which contains several species in other parts of the world, also reputed venomous. Walckenaër, writing of the Latrodectus malmignatus, an allied species, common in Sardinia, Corsica, and parts of Italy, remarks :- "This spider is certainly poisonous; its bite causes, they say, in man pain, lethargy, and sometimes fever " "and Mr. Abbot, in his account of Latrodectus in his "Georgian Spiders," states that its bite is "undoubtedly venomous." It is curious, also, as already noticed by Dr. Powell, that the species of this genus, so widely distributed over the world as to be found in Europe, America, Australia, and New Zealand, should all agree in being black with red markings, for colour is of all characteristics the most variable, and especially so in the case of spiders. 